E3S Web of Conferences 1, 19002 (2013)

DOI: $10.1051 / \mathrm{e} 3 \operatorname{sconf} / 20130119002$

(c) Owned by the authors, published by EDP Sciences, 2013

\title{
Mercury speciation and mobility in mine wastes from mercury mines in China
}

\author{
P. $\mathrm{Li}^{1}$ and X. Feng ${ }^{2}$ \\ ${ }^{1}$ State Key Laboratory of Environmental Geochemistry, Institute of Geochemistry, Chinese Academy of Sciences, \\ Guiyang, 550002, China, ping_ligyig@163.com \\ ${ }^{2}$ State Key Laboratory of Environmental Geochemistry, Institute of Geochemistry, Chinese Academy of Sciences, \\ Guiyang, 550002, China, fengxinbin@vip.skleg.cn
}

\begin{abstract}
Mine wastes calcines were formed through retorting of cinnabar ores at high temperature, which are considered as significant sources of mercury $(\mathrm{Hg})$ contamination to the local environment. To better understand the role of mine waste in $\mathrm{Hg}$ geochemical cycle in $\mathrm{Hg}$ mining areas, $\mathrm{Hg}$ speciation and mobility were evaluated in mine waste calcines and waste rocks from $9 \mathrm{Hg}$ mines in China. The total mercury $(\mathrm{THg})$ concentrations in the mine wastes ranged from 0.369 to $2620 \mathrm{mg} \cdot \mathrm{kg}^{-1}$ and varied widely in different $\mathrm{Hg}$ mines. Cinnabar and $\mathrm{Hg}^{0}$ are dominant forms in the mine wastes. The calcines had significant higher $\mathrm{Hg}^{2+}{\mathrm{and} \mathrm{Hg}^{0}}^{0}$ concentrations than the waste rocks, which indicated the retorting process can produce large amounts of secondary by-product $\mathrm{Hg}$ compounds. The leaching experiment confirmed mine wastes were important $\mathrm{Hg}$ pollution sources to local aquatic system. The mine wastes are also significant $\mathrm{Hg}$ sources to the atmosphere.
\end{abstract}

Keywords: mercury; speciation; mobility; mine waste; calcines

\section{Introduction}

Mercury mines are considered as hot spots of $\mathrm{Hg}$ pollution. During the processing of $\mathrm{Hg}$ ores, secondary $\mathrm{Hg}$ phases form and accumulate in mine waste calcines, which are more soluble than cinnabar and can cause a greater extent of $\mathrm{Hg}$ contamination to the surrounding environment. Mine wastes are considered as significant sources of $\mathrm{Hg}$ contamination to the surrounding aquatic ecosystems. China is rich in $\mathrm{Hg}$ mineral resources and most $\mathrm{Hg}$ mines are distributed in southwestern China. Guizhou province is the most important $\mathrm{Hg}$ production center, with approximately 80000 tons of $\mathrm{Hg}$ reserves. The long history of mining activities have produced large amount of mine wastes in the $\mathrm{Hg}$ mining area, which have not been properly treated. This study was designed to: (1) evaluate $\mathrm{Hg}$ speciation in the mine waste from different $\mathrm{Hg}$ mines in China; and (2) simulate the mobilization of $\mathrm{Hg}$ by runoff under the environmental conditions.

\section{Materials and Methods}

A total of $9 \mathrm{Hg}$ mines in China were selected in this study. Wanshan, Danzhai, Xiushan and Xunyang are ranked as super-large $\mathrm{Hg}$ mines. Wanshan is located in eastern
Guizhou Province and is known as the "capital of $\mathrm{Hg}$ " because it was the largest $\mathrm{Hg}$ mine in China. Its total $\mathrm{Hg}$ production was estimated to be 30,000 tons from the 1950s to 2003. Xunyang $\mathrm{Hg}$ mine is located in southern Shaanxi province and is the only large scale $\mathrm{Hg}$ mine in operation in China. Three large (Tongren, Chatian and Xinhuang) and two medium (Sandu and Yulan) Hg mines were also selected in this study. A total of 132 mine waste samples were collected from these $9 \mathrm{Hg}$ mines, which included 91 calcines and 41 waste rocks. The mine waste samples were determined for total mercury (THg), elemental $\mathrm{Hg}\left(\mathrm{Hg}^{0}\right)$ and $\mathrm{Hg}^{2+}$ and for leaching experiment.

\section{Results and Discussion}

The THg concentrations in the mine waste samples from different $\mathrm{Hg}$ mines varied widely from 0.369 to 2620 $\mathrm{mg} \cdot \mathrm{kg}^{-1}$ (Fig. 1) and followed a log-normal distribution with a geo-mean of $18.8 \mathrm{mg} \cdot \mathrm{kg}^{-1}$. The geo-means of $\mathrm{THg}$ concentrations in the calcines and waste rocks were 18.2 and $20.1 \mathrm{mg} \cdot \mathrm{kg}^{-1}$, respectively, which were significantly higher than the baseline of $0.35 \mathrm{mg} \cdot \mathrm{kg}^{-1}$ in rocks reported in Wanshan area. The waste rocks had significant higher $\mathrm{THg}$ concentrations than the calcines $(\mathrm{p}<0.01)$, which indicated probable existence of cinnabar in the waste 
rocks.

The $\mathrm{Hg}^{2+}$ concentrations in the calcines and waste rocks varied from 0.002 to $3.81 \mathrm{mg} \cdot \mathrm{kg}^{-1}$ (with a mean of $0.52 \mathrm{mg} \cdot \mathrm{kg}^{-1}$ ) and from 0.003 to $8.33 \mathrm{mg} \cdot \mathrm{kg}^{-1}$ (with a mean of $\left.0.65 \mathrm{mg} \cdot \mathrm{kg}^{-1}\right)$, respectively. The calcines had significant higher percentages of $\mathrm{Hg}$ as $\mathrm{Hg}^{2+}$ (with a mean of $1.8 \%$ ) than the waste rocks (with a mean of $0.4 \%)$. Three relative high values of $\mathrm{Hg}^{2+}$ ratio $(6.88 \%$, $9.30 \%$ and $10.6 \%$ ) were all found in the calcines, which indicated the retorting process can produce large amounts of secondary by-product water soluble $\mathrm{Hg}$ compounds in the calcines. A significant correlation $(r=0.60, p<0.001)$ was found between the $\mathrm{Hg}^{2+}$ and $\mathrm{THg}$ concentrations in the mine waste, which indicated the presence of significant ionic $\mathrm{Hg}^{2+}$ in the mine waste.

The $\mathrm{Hg}^{0}$ concentrations in the calcines and waste rocks ranged from 0.22 to $79 \mathrm{mg} \cdot \mathrm{kg}^{-1}$ and from 0.14 to 15 $\mathrm{mg} \cdot \mathrm{kg}^{-1}$, respectively. The calcines had significant higher $\mathrm{Hg}^{0}$ concentrations (with a mean of $16 \mathrm{mg} \cdot \mathrm{kg}^{-1}$ ) than the waste rocks (with a mean of $6.2 \mathrm{mg} \cdot \mathrm{kg}^{-1}$ ). During $\mathrm{Hg}$ ore retorting process, most $\mathrm{Hg}$ compounds are converted to $\mathrm{Hg}^{0}$ at high temperatures. Some $\mathrm{Hg}^{0}$ in the gas phase is re-adsorbed to matrix components when the material cooled down. A significant correlation $(r=0.43, p<0.05)$ was found between $\mathrm{Hg}^{0}$ and $\mathrm{THg}$ concentrations in the mine waste samples.

The percentages of $\mathrm{Hg}$ as $\mathrm{Hg}^{2+}$ and $\mathrm{Hg}^{0}$ in the calcines were higher than those in the waste rocks (Fig.
2). The major form of $\mathrm{Hg}$ in the mine waste is cinnabar, which is very insoluble and much less volatile and leachable than other forms of $\mathrm{Hg}$.

During leaching experiment, highly variable $\mathrm{TSHg}$ concentrations were found in the leachates. The mean of TS-Hg concentration in the leachates was $0.45 \mu \mathrm{g} \cdot \mathrm{L}^{-1}$ with a range of $0.012-2.8 \mu \mathrm{g} \cdot \mathrm{L}^{-1}$. It only accounted small portion of $\mathrm{THg}$ in the mine waste (with a mean of $0.051 \%$ and a range of $0.0020-0.61 \%$ ). There are no significant differences of TS-Hg concentration in the leachates from calcines and waste rock. A significant correlation $(\mathrm{r}=0.72, \mathrm{p}<0.001)$ between leachate $\mathrm{TSHg}$ concentrations and $\mathrm{THg}$ concentrations in the corresponding mine waste leached was observed.

\section{Conclusion}

The THg, $\mathrm{Hg}^{2+}$ and $\mathrm{Hg}^{0}$ concentrations in mine waste varied widely in different $\mathrm{Hg}$ mines. Cinnabar and $\mathrm{Hg}^{0}$ are dominant forms in the mine waste. The calcines had significant higher $\mathrm{Hg}^{2+}$ and $\mathrm{Hg}^{0}$ concentrations than the waste rock, which indicated $\mathrm{Hg}$ in the calcines is more active. High TSHg, $\mathrm{Hg}^{2+}$ and $\mathrm{Hg}^{0}$ concentrations in the mine wastes indicated that mine wastes are significant $\mathrm{Hg}$ sources to the local aquatic system and the atmosphere. Remedial techniques are required to fix the $\mathrm{Hg}$ in the mine waste calcines and to reduce $\mathrm{Hg}$ release to the local environment

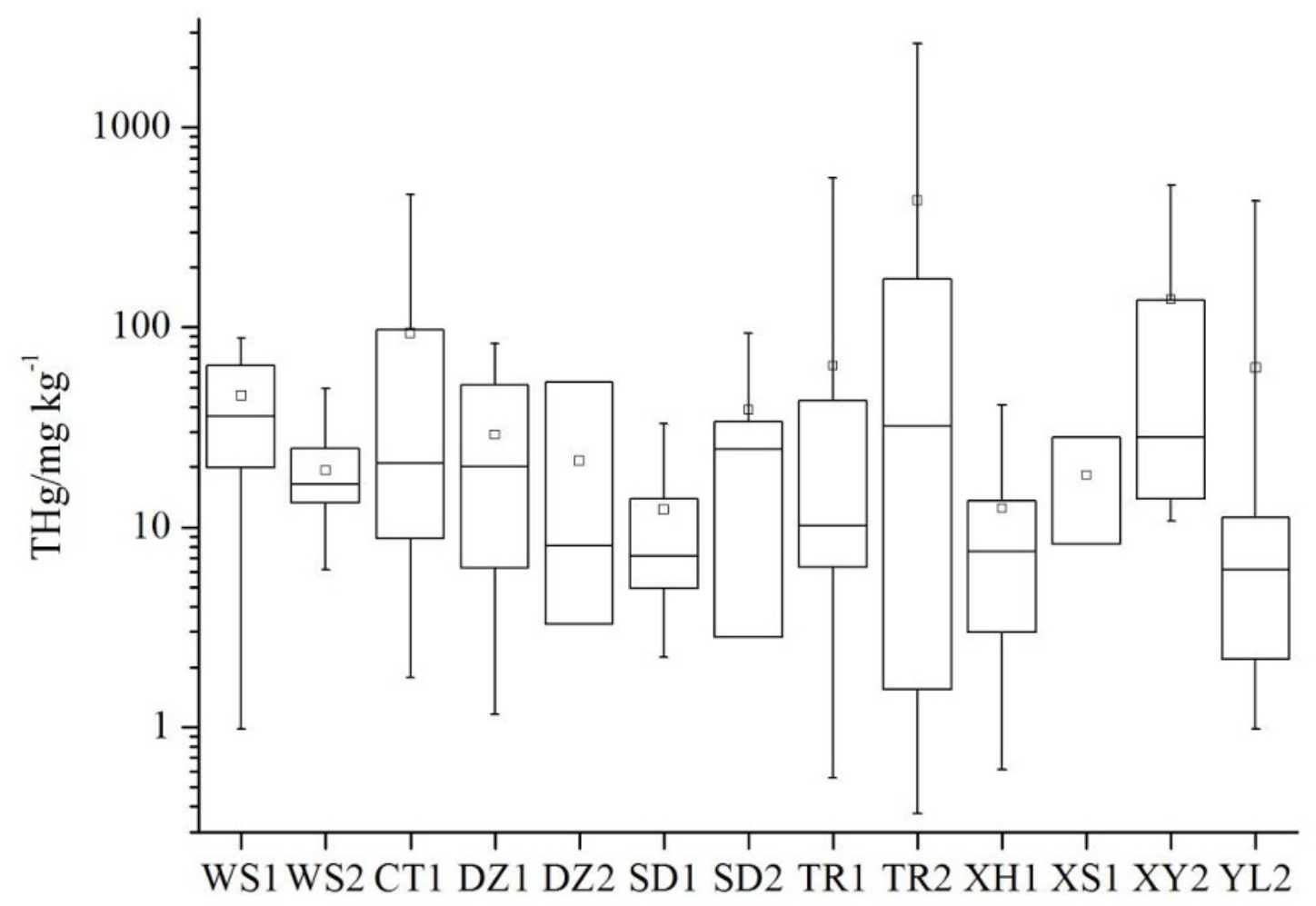

Fig.1 THg concentrations in the calcines and waste rocks from different $\mathrm{Hg}$ mines in China. 1, calicines; 2, waste rock; each box represents interquartile range (25th and 75th percentile), the band near the middle of the box is the 50th percentile (the median), and the whisker represents 5th and 95th percentile 


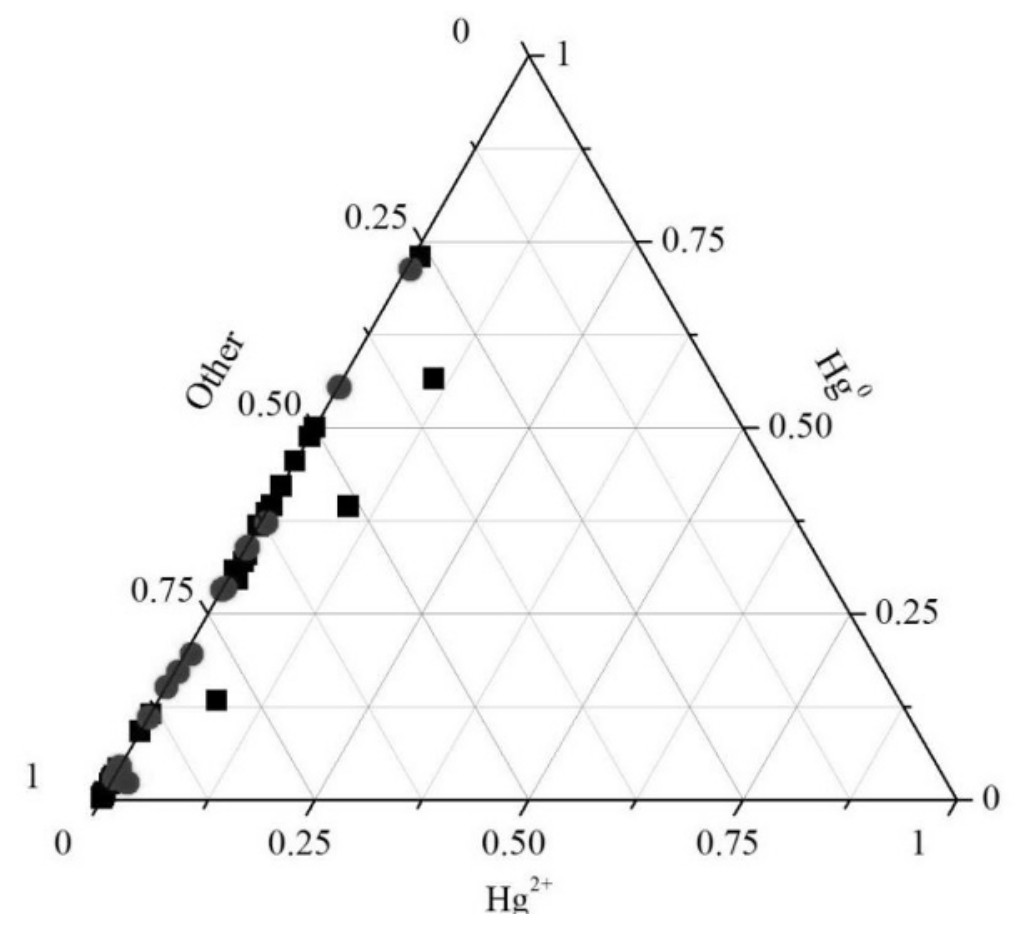

Fig.2 Triangle diagram showing $\mathrm{Hg}$ speciation distributions in mine wastes from $\mathrm{Hg}$ mines in China

\section{Acknowledgements}

This study was funded by the Natural Science Foundation of Guizhou Province (2009-No.2003), West
Light Foundation of the Chinese Academy of Sciences and National Natural Science Foundation of China (21007068, 41021062). 